\title{
Effect of Surface Morphology and Dispersion Media on the Properties of PEDOT:PSS/n-Si Hybrid Solar Cell Containing Functionalized Graphene
}

\author{
Pham Van Trinh, ${ }^{1}$ Phan Ngoc Hong, ${ }^{1,2}$ Bui Hung Thang, ${ }^{1}$ Nguyen Tuan Hong, \\ Duong Van Thiet, ${ }^{4}$ Nguyen Van Chuc, ${ }^{1,2}$ and Phan Ngoc Minh ${ }^{1,2,3}$ \\ ${ }^{1}$ Institute of Materials Science, Vietnam Academy of Science and Technology, 18 Hoang Quoc Viet Str., Cau Giay Distr., Hanoi, Vietnam \\ ${ }^{2}$ Graduate University of Science and Technology, Vietnam Academy of Science and Technology, 18 Hoang Quoc Viet Str., \\ Cau Giay Distr., Hanoi, Vietnam \\ ${ }^{3}$ Center for High Technology Development, Vietnam Academy of Science and Technology, 18 Hoang Quoc Viet Str., \\ Cau Giay Distr., Hanoi, Vietnam \\ ${ }^{4}$ School of Engineering Physics, Hanoi University of Science and Technology, 1 Dai Co Viet Road, Hai Ba Trung Distr., Hanoi, Vietnam
}

Correspondence should be addressed to Pham Van Trinh; trinhpv@ims.vast.vn and Phan Ngoc Minh; pnminh@vast.ac.vn

Received 22 June 2017; Revised 5 October 2017; Accepted 15 October 2017; Published 6 November 2017

Academic Editor: Mikhael Bechelany

Copyright (C) 2017 Pham Van Trinh et al. This is an open access article distributed under the Creative Commons Attribution License, which permits unrestricted use, distribution, and reproduction in any medium, provided the original work is properly cited.

\begin{abstract}
We present the results on the effect of surface morphology and dispersion media on the properties of PEDOT:PSS/n-Si hybrid solar cell containing functionalized graphene (Gr). The hybrid solar cells based on SiNWs showed higher power conversion efficiency (PCE) compared to the planar based cells due to suppressing the carrier recombination and improving carrier transport efficiency. The PCE of hybrid solar cells could be improved by adding Gr into PEDOT:PSS. Different solvents including deionized (DI) water, ethylene glycol (EG), and isopropyl alcohol (IPA) were used as media for Gr dispersion. The best performance was obtained for the cell containing Gr dispersed in EG with a measured PCE of 7.33\% and nearly 13\% and 16\% enhancement in comparison with the cells using Gr dispersed in IPA and DI water, respectively. The increase in PCE is attributed to improving the carrier-mobility, electrical conductivity, PEDOT crystallinity, and ordering.
\end{abstract}

\section{Introduction}

Traditional sources of energy like petroleum, coal, and natural gas are being depleted off due to high usage rate which is further expected to rise in the future. Solar energy is by far the renewable energy source with the most significant potential. Utilization of solar energy is very expensive and therefore not widely used for commercial electricity production. Demanding for the development of the next generations of solar cell with higher efficiency, lower price and longer life are indispensable.

Nanomaterials and nanostructures based solar cells hold promising potency to enhance the performance of solar cells by improving both light trapping and photocarrier collection $[1,2]$. Many approaches have been taken to lower the production cost of Si PVs, among which thin-film Si solar cells offer a promising low-cost solution. However, thin-film $\mathrm{Si}$ solar cells have lower efficiency than bulk $\mathrm{Si}$, due to their limited absorption thickness [3-5]. As evidenced by recent literature reports, silicon nanowire (SiNW) array exhibits not only perfect absorption but also a high surface to volume ratio compared to planar Si. Consequently, the next generation solar cells based on SiNW have attracted a great interest of scientists, engineers, and technology developers due to their potential for higher conversion efficiency and being cost-effective compared to the conventional bulk Si solar cell generation [6-10]. Unfortunately, all-inorganic solar cells based on SiNW usually require energy-intensive semiconductor processes, including high-temperature thermal diffusion, thermal annealing of the electrodes, and high-vacuum 
chemical deposition processes and hence it will lead to increase the manufacturing costs. For this reason, hybrid solar cells with radial heterojunctions that combine an organic with SiNW have been actively developed [10-14]. They not only require low-temperature fabrication due to the low thermostability of the organic material and solutionbased processes but also can realize lower manufacturing costs by utilizing inexpensive and abundant organic materials $[14,15]$. Besides, the cell might be useful for applications where low weight, mechanical flexibility, and disposability are essential $[10,11]$. There are a large number of reports on organic/inorganic hybrid solar cells with good power conversion efficiency in which a thin layer of conducting polymer poly(3,4-ethylenedioxythiophene):poly(styrenesulfonate) (PEDOT:PSS) is coated on $\mathrm{Si}$ nanowires to form the photovoltaic junction [16]. The problem here is the polymer chains of PEDOT are too large to infiltrate into small gaps inside the SiNW array and thus incomplete coverage of the SiNW surfaces by the PEDOT is expected and consequently reduces the efficiency of the device, as well as creating unstable interfaces leading to inhomogeneous conductivity [17]. Several studies have been done to improve the stability against temperature, moisture, and chemical degradation in solar devices as well as the uniform dispersion of conducting polymer on Si substrate by using carbon nanotubes fullerenes and graphene oxide [17-20]. Besides its reliability, low production costs, and large-scale production capability, Gr exhibits excellent properties such as low-sheet resistance, high transmittance, unique mechanical properties, and good thermal and chemical stability [21]. Moreover, Gr could well disperse in water and combine with a variety of organic and/or inorganic materials in solution [21]. Therefore, graphene can be used as a transparent electrode, active interfacial layer, electron transport layer, hole transport layer, or electron/hole separation layer in combination with the conducting polymers for hybrid solar cell fabrication [2123]. However, the problem here is how to disperse $\mathrm{Gr}$ in PEDOT:PSS and knowing which medium is the best for not only obtaining the uniform dispersion but also improving the performance of hybrid solar cells. There are still questions needing to be clarified and further investigated.

Thus, this study is to investigate the effect of surface morphology and dispersion media on the properties of PEDOT:PSS/n-Si hybrid solar cell containing functionalized Gr. Gr was functionalized with carboxyl $(\mathrm{COOH})$ functional group and then dispersed in different media including DI water, EG, and IPA. The properties of hybrid solar cells were investigated to find the best dispersion media to obtain the highest efficiency.

\section{Experimental Procedure}

2.1. Materials. Graphite rods (99.99\% purity) used as electrodes to synthesize graphene sheets were purchased from Sigma-Aldrich. Acetone, ethanol, sulfuric acid $\left(\mathrm{H}_{2} \mathrm{SO}_{4}\right)$, hydrogen peroxide $\left(\mathrm{H}_{2} \mathrm{O}_{2}\right)$, and nitric acid $\left(\mathrm{HNO}_{3}\right)$, supplied by Xilong Chemical Co., Ltd. (China), were used for Si cleaning and graphene functionalization process. N-type Si (100) wafers $(1-50 \Omega \cdot \mathrm{cm})$, silver nitrate $\left(\mathrm{AgNO}_{3}\right)$, and hydrofluoric
(HF) acid purchased from Sigma-Aldrich were used for preparing the SiNWs. PEDOT:PSS purchased from SigmaAldrich were used as a hole transport layer for the hybrid solar cell. EG and IPA supplied by VWR Chemicals were used as base fluids for graphene dispersion. Silver and aluminum targets purchased from Kojundo Chemical Laboratory Co. were used for preparing the front and rear electrodes.

2.2. Preparation of Hybrid Solar Cells. Schematic diagram of the fabrication process of SiNW/PEDOT:PSS/Gr hybrid solar is described in Figure 1. Graphene sheets are synthesized by a plasma-assisted electrochemical exfoliation process [24]. $\mathrm{Gr}$ was then in the mixture of acid $\left(\mathrm{HNO}_{3}: \mathrm{H}_{2} \mathrm{SO}_{4}, 1: 3\right)$ at $70^{\circ} \mathrm{C}$ in $5 \mathrm{~h}$ under continuous magnetic stirring to create the $\mathrm{Gr}-\mathrm{COOH}$. After functionalization process, the prepared Gr-COOH was cleaned by distilled water and finally dispersed in deionized (DI) water, EG, and IPA to make Gr$\mathrm{COOH}$ solutions in different dispersion environments with a concentration of $1 \mathrm{mg} / \mathrm{ml}$ by ultrasonication for $30 \mathrm{~min}$. The prepared $\mathrm{Gr}-\mathrm{COOH}$ solutions were added to PEDOT:PSS by magnetic stirring at room temperature for 6 hours to form PEDOT:PSS/Gr solutions consisting of $99.5 \mathrm{wt} \%$ PEDOT:PSS and 0.5 wt.\% Gr.

SiNW arrays prepared by chemical etching method were reported earlier [25]. The Si substrates $(1 \mathrm{~cm} \times 1 \mathrm{~cm})$ were cleaned by ultrasonication in acetone, ethanol, and DI water for $10 \mathrm{~min}$ each and then in piranha solution consisting of $\mathrm{H}_{2} \mathrm{SO}_{4}$ and $\mathrm{H}_{2} \mathrm{O}_{2}(4: 1, \mathrm{v} / \mathrm{v})$ at $130^{\circ} \mathrm{C}$ for $10 \mathrm{~min}$, followed by rinsing with deionized water for $10 \mathrm{~min}$ and with a $2 \%$ hydrofluoric acid (HF) solution for $2 \mathrm{~min}$ to remove organic compounds and native oxides. The cleaned silicon wafers were immersed in an aqueous $\mathrm{HF}$ solution $(4.6 \mathrm{M})$ containing $\mathrm{AgNO}_{3}(0.02 \mathrm{M})$ for $6 \mathrm{~min}$ to form SiNWs. As-prepared SiNW samples were then rinsed in deionized water and $\mathrm{HNO}_{3}(35 \%)$ for $10 \mathrm{~min}$ to remove any residue of the silver catalyst.

To prepare the hybrid solar cells, the Si substrates including planar Si and SiNWs were cleaned firstly with piranha solution for $20 \mathrm{~min}$ at $130^{\circ} \mathrm{C}$ and then with a $2 \% \mathrm{HF}$ solution for $2 \mathrm{~min}$ to remove any native oxides. Immediately, the prepared PEDOT:PSS/Gr solutions were spin-coated onto the SiNW surface with speed of $6000 \mathrm{rpm}$ for $60 \mathrm{~s}$ and then annealing at $140^{\circ} \mathrm{C}$ for $30 \mathrm{~min}$ in $\mathrm{N}_{2}$ environment to remove any residual water inside the PEDOT:PSS to form the hybrid structure. Finally, a thin layer of Al-film with a thickness of $500 \mathrm{~nm}$ was deposited on the backside of the substrate to form a rear electrode and a finger-typed Ag-film thickness of $250 \mathrm{~nm}$ was deposited on the top of the substrate to form a front electrode via a shadow mask process by thermal evaporation. A planar PEDOT:PSS/n-Si and PEDOT:PSS/nSiNWs hybrid solar cells without $\mathrm{Gr}$ were also fabricated using the same process for the comparison. The hybrid solar cells with different surface morphologies and chemical compositions were noted as $\mathrm{P} 0, \mathrm{P} 1, \mathrm{~W} 0, \mathrm{~W} 1, \mathrm{~W} 2$, and $\mathrm{W} 3$ as presented in Table 1.

2.3. Characterization. The morphological study was characterized by Hitachi S4800 field emission scanning electron microscope (FESEM) and JEOL JEM-2100 high-resolution 


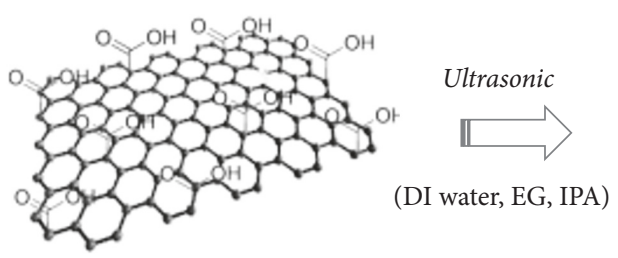

$\mathrm{Gr}-\mathrm{COOH}$

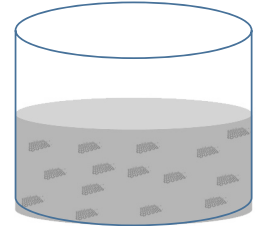

Gr-COOH solution

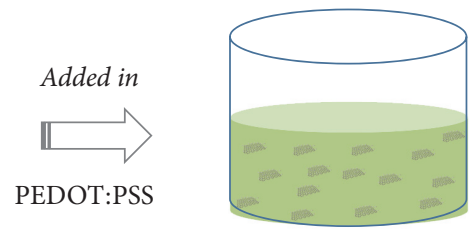

PEDOT:PSS/Gr solution
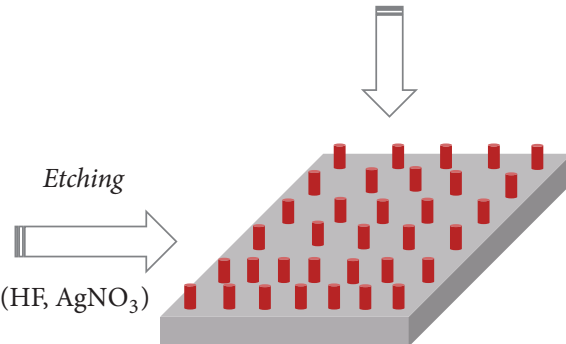

N-type SiNWs
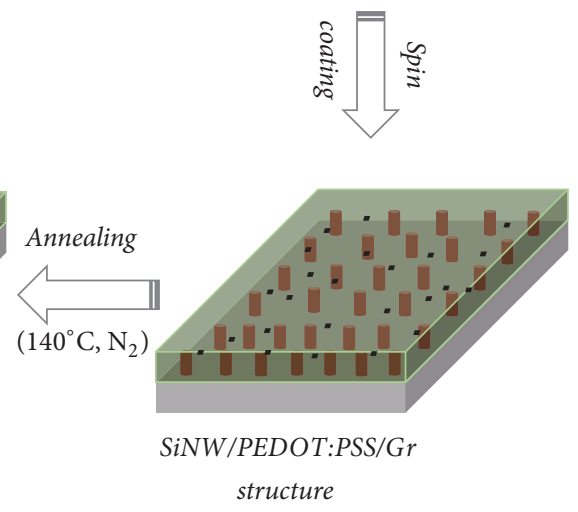

$\left(140^{\circ} \mathrm{C}, \mathrm{N}_{2}\right)$

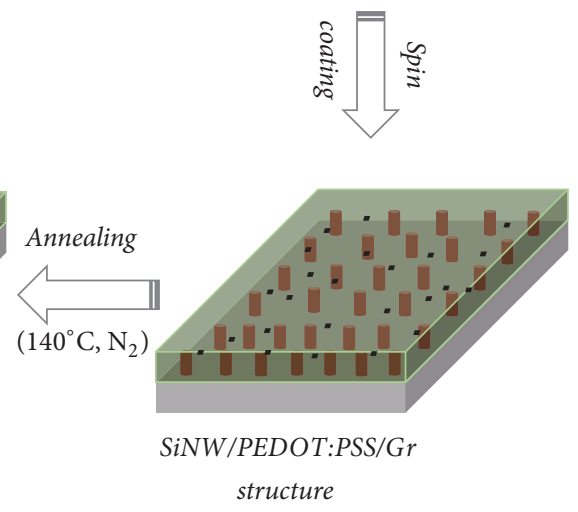

SiNW/PEDOT:PSS/Gr

structure
SiNW/PEDOT:PSS/Gr hybrid solar cell
SiNW/PEDOT:PSS/Gr

structure

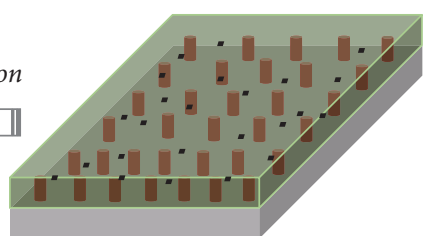

FIGURE 1: Schematic diagram of the fabrication process of PEDOT:PSS/SiNW hybrid solar cell containing functionalized graphene.

TABLE 1: Chemical composition and photovoltaic properties of the prepared hybrid solar cells: short circuit current density $\left(J_{\text {sc }}\right)$, open circuit voltage $\left(V_{\text {oc }}\right)$, series resistance $\left(R_{s}\right)$, Fill factor $(\mathrm{FF})$, and efficiency $(\eta)$.

\begin{tabular}{|c|c|c|c|c|c|c|c|c|}
\hline Sample & Compositions & PEDOT:PSS (wt.\%) & Graphene (wt.\%) & $J_{\mathrm{sc}}\left(\mathrm{mA} / \mathrm{cm}^{2}\right)$ & $V_{\mathrm{oc}}(\mathrm{V})$ & $R_{s}\left(\Omega / \mathrm{cm}^{2}\right)$ & $\mathrm{FF}(\%)$ & $\eta(\%)$ \\
\hline P0 & Planar Si + PEDOT:PSS & 100 & 0 & 17.34 & 0.40 & 8.03 & 52 & 3.68 \\
\hline $\mathrm{P} 1$ & Planar Si + PEDOT:PSS + Gr & 99.5 & 0.5 & 18.48 & 0.41 & 4.21 & 58 & 4.37 \\
\hline W0 & SiNWs + PEDOT:PSS & 100 & 0 & 19.97 & 0.44 & 6.58 & 60 & 5.33 \\
\hline W1 & SiNWs + PEDOT:PSS + Gr (in DI) & 99.5 & 0.5 & 21.34 & 0.46 & 3.12 & 64 & 6.43 \\
\hline W2 & SiNWs + PEDOT:PSS + Gr (in EG) & 99.5 & 0.5 & 22.42 & 0.46 & 2.63 & 70 & 7.33 \\
\hline W3 & SiNWs + PEDOT:PSS + Gr (in IPA) & 99.5 & 0.5 & 22.17 & 0.45 & 2.82 & 66 & 6.50 \\
\hline
\end{tabular}

transmission electron microscopy (HRTEM). FTIR spectra were performed in range of 500 to $4000 \mathrm{~cm}^{-1}$ using a SHIMADZU IR Prestige21 Spectrometer. The Raman spectra were recorded using a iHR550 Jobin-Yvon spectrometer using a $514 \mathrm{~nm}$ laser excitation at room temperature. Optical reflectance spectra were measured by using Jaccob V-570 UV/Vis/NIR spectrophotometer. The current-voltage characteristics of solar cells were measured under illumination of air mass (AM) $1.5 \mathrm{G}$ with intensity of $100 \mathrm{~mW} \cdot \mathrm{cm}^{-2}$ using a Keithley 2400 source meter.

\section{Results and Discussion}

Figure 2(a) shows a typical SEM image of graphene sheets. As can be seen, the length of Gr sheets was estimated to be about few micrometers. The structure of $\mathrm{Gr}$ sheets was deeply investigated by HRTEM. As shown in Figure 2(b), the number of layers of $\mathrm{Gr}$ sheets was determined to be around 10-15 layers and Gr sheets in this work had an average thickness of $5 \mathrm{~nm}$. Raman spectra of $\mathrm{Gr}$ and $\mathrm{Gr}$ $\mathrm{COOH}$ were shown in Figure 2(c). As a result, the D band 


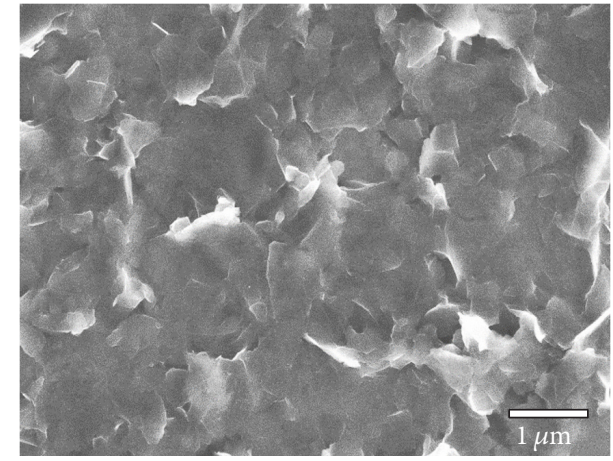

(a)

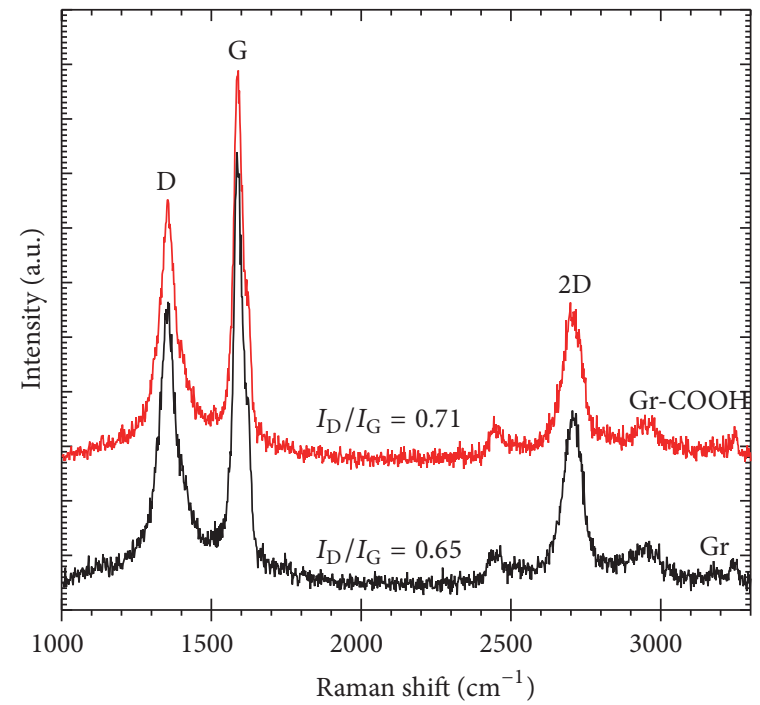

(c)

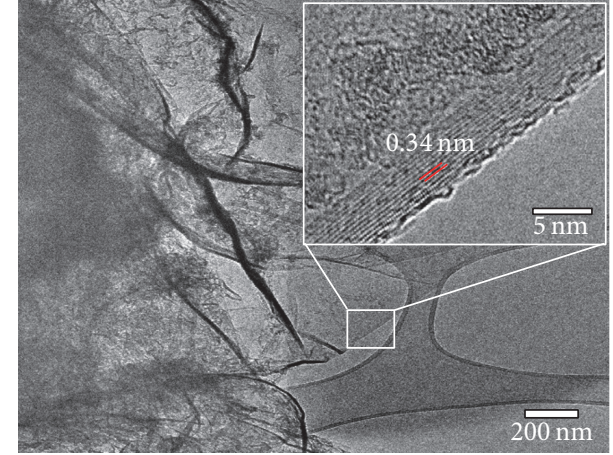

(b)

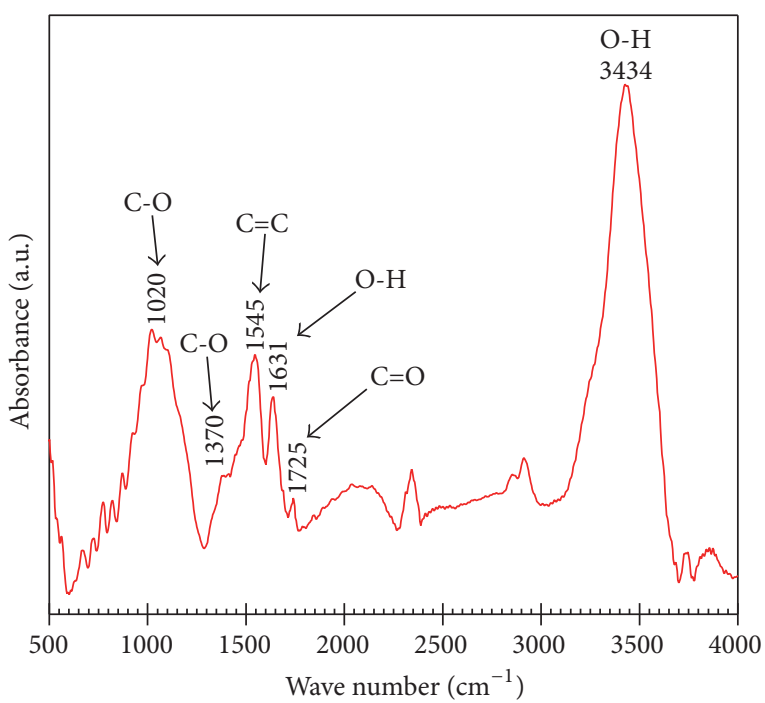

(d)

FIgURE 2: (a) SEM image, (b) TEM image, (c) Raman spectra, and (d) FTIR spectra of Gr-COOH.

(around $1351 \mathrm{~cm}^{-1}$ ) and $\mathrm{G}$ band (around $1591 \mathrm{~cm}^{-1}$ ) appear in all of the samples. D band presents as defect, disorder, or $\mathrm{sp}^{3}$ hybridized carbon atoms. $\mathrm{G}$ band presents as a typical peak of the graphitic structure due to vibration of carbon atoms. However, the intensity ratio of $\mathrm{D}$ band and $\mathrm{G}$ band $\left(I_{\mathrm{D}} / I_{\mathrm{G}}\right)$ of each sample is different compared to the others. The $I_{\mathrm{D}} / I_{\mathrm{G}}$ ratio of Gr-COOH is higher than that of Gr. This could be due to the functionalization process using chemical reagents causing some defects on the graphitic structure of graphene. Figure 2(d) shows a FTIR spectrum of Gr-COOH. The several typical peaks were detected such as $3434 \mathrm{~cm}^{-1}$ and $1725 \mathrm{~cm}^{-1}$ assigned to $\mathrm{O}-\mathrm{H}$ stretching vibrations $\left(\nu_{\mathrm{OH}}\right)$ and the stretching vibrations $\left(\nu_{\mathrm{C}=\mathrm{O}}\right)$ of the carboxyl group, respectively. Besides, the peaks at $1370 \mathrm{~cm}^{-1}$ and $1020 \mathrm{~cm}^{-1}$ are assigned to $\mathrm{O}-\mathrm{H}$ bonding $\left(\nu_{\mathrm{O}-\mathrm{H}}\right)$ and $\mathrm{C}-\mathrm{O}$ stretching vibrations mode $\left(\nu_{\mathrm{C}-\mathrm{O}}\right)$ of carboxyl group [26]. Also, the peak at $1545 \mathrm{~cm}^{-1}$ attributed to the typical in-plane vibration $(\mathrm{C}=\mathrm{C})$ of the graphitic structure of graphene. As a result, the Gr-COOH was successfully prepared by treatment with a mixture of nitric and sulfuric acids.

Figure 3 shows the top-viewed and cross-sectional SEM images of the as-prepared SiNW array and after coated
PEDOT:PSS/Gr. From top-viewed SEM image, we can see that the SiNWs were grown by the chemical etching process with high density and diameter in the range of 100 to $200 \mathrm{~nm}$. The length of SiNWs was also determined with an average length of $800 \mathrm{~nm}$ by cross-sectional SEM image (Figure 3(b)). After the coating process, SiNW array seems to be fully covered by PEDOT:PSS/Gr as observed in Figure 3(c). However, in the cross-sectional mode (Figure 3(d)), we can see that PEDOT:PSS/Gr was not wholly infiltrated between the gap of SiNWs. This was attributed to either small gap between SiNWs or large length of Gr sheets. The infiltration of PEDOT:PSS/Gr only happening on the top of SiNWs may be a critical reason leading to the decrease of the PCE of solar cell devices compared to the expected values.

Structural properties of SiNW/PEDOT:PSS and SiNW/ PEDOT:PSS/Gr structures were investigated using Raman spectroscopy. As shown in Figure 4, several typical peaks were detected in the Raman spectra. The peak at $520 \mathrm{~cm}^{-1}$ recorded in both structures is assigned to the n-typed $\mathrm{Si}$ substrate. Other peaks located at $1438 \mathrm{~cm}^{-1}, 1499 \mathrm{~cm}^{-1}$, and $1531 \mathrm{~cm}^{-1}$ were also detected in both samples. According to Lindfors et al., the vibration of $\mathrm{C}=\mathrm{C}$ bonding can be addressed by Raman 


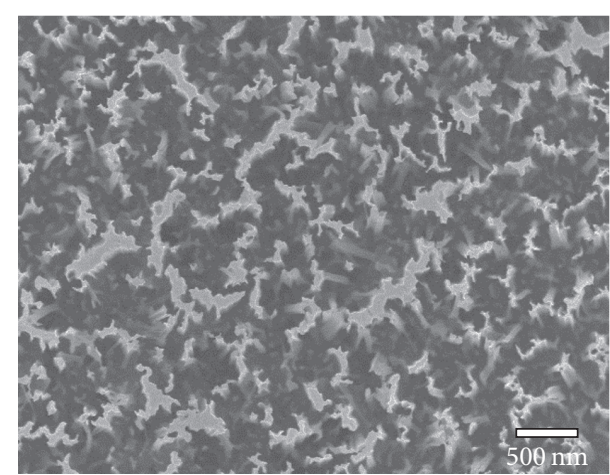

(a)

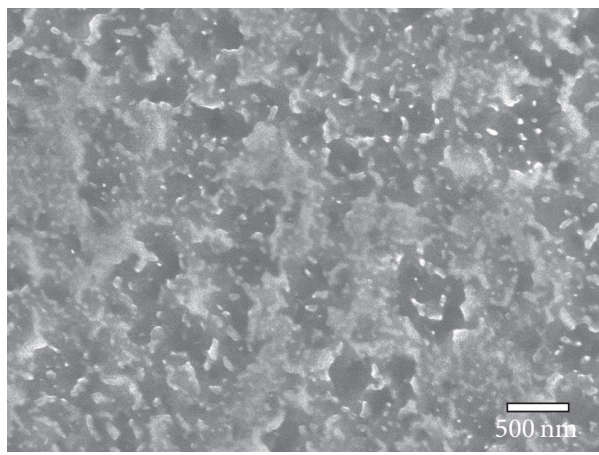

(c)

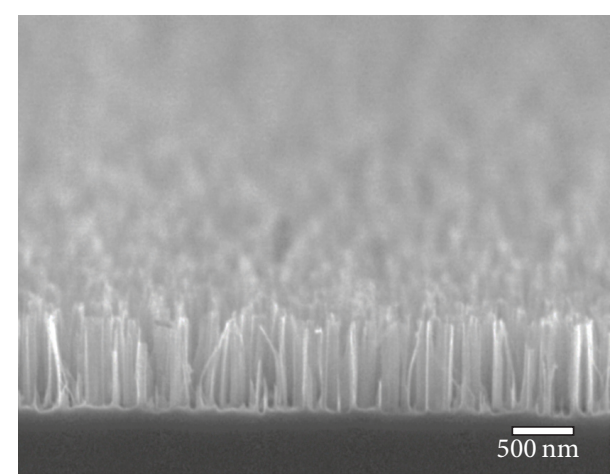

(b)

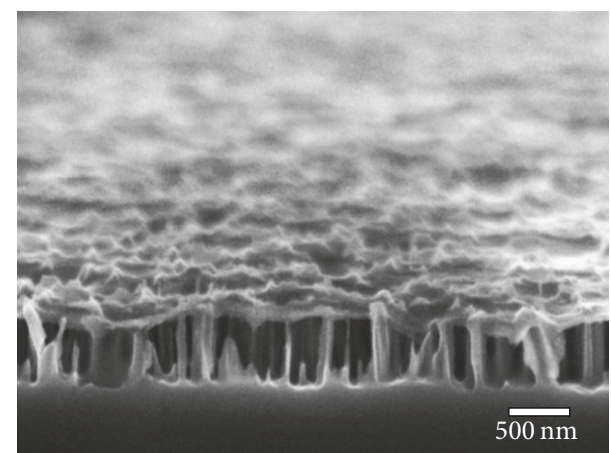

(d)

FIGURE 3: Top-viewed and cross-sectional SEM images of (a-b) SiNW arrays and (c-d) after coated PEDOT:PSS/Gr.

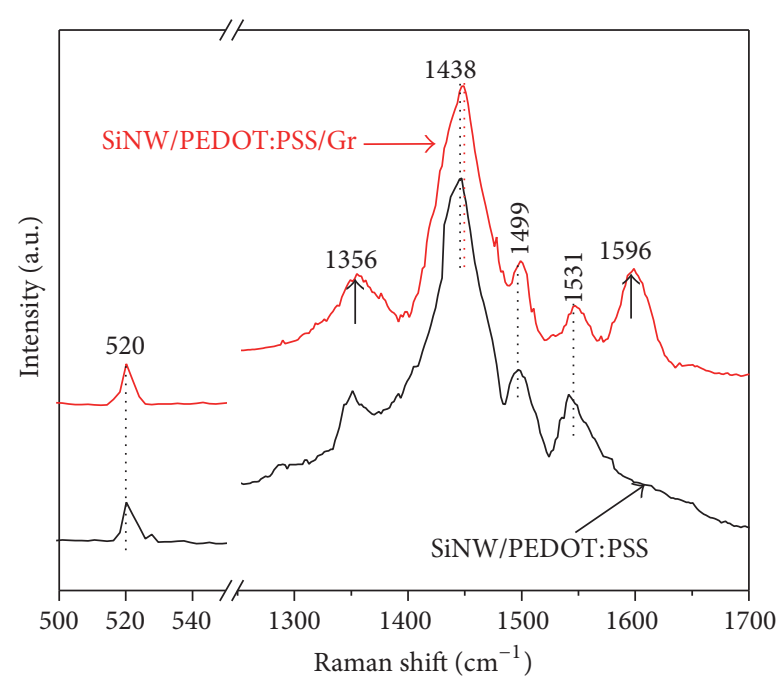

FIGURE 4: Raman spectra of SiNW/PEDOT:PSS and SiNW/ PEDOT:PSS containing functionalized Gr.

spectra via typical bands at around $1600 \mathrm{~cm}^{-1}, 1440 \mathrm{~cm}^{-1}$, and $1500 \mathrm{~cm}^{-1}$ corresponding to antisymmetric, symmetric, and asymmetric $\mathrm{C}=\mathrm{C}$ stretching, respectively [27]. The presence of PEDOT:PSS could be confirmed with the peaks at the band of $1400-1500 \mathrm{~cm}^{-1}$ resulting in the thiophene ring of PEDOT resonating between two states of benzoid and quinoid [28].
The peaks confirm the presence of Gr in the PEDOT:PSS detected at $1356 \mathrm{~cm}^{-1}$ and $1596 \mathrm{~cm}^{-1}$ corresponding to $D$ and $\mathrm{G}$ bands, respectively. It is noted that the Raman peak of pristine PEDOT:PSS was recorded at $1435 \mathrm{~cm}^{-1}$. This peak is slightly shifted to higher wave number $\left(1438 \mathrm{~cm}^{-1}\right)$ when $\mathrm{Gr}$ is added. The shift of the peak is due to the transformation of the PEDOT:PSS resonance structure after Gr is added and $\pi-\pi$ interaction between $\mathrm{Gr}$ and the aromatic structure of PEDOT:PSS [29].

Figure 5 shows the reflectance spectra of a planar Si wafer, a planar Si coated PEDOT:PSS, a planar Si coated PEDOT:PSS/Gr, SiNWs, SiNWs coated PEDOT:PSS, and SiNW coated PEDOT:PSS/Gr over a broad spectral range from 220 to $2000 \mathrm{~nm}$. From the spectra, we can see the sharp transition around $1000-1150 \mathrm{~nm}$ that corresponds to the band edge of $\mathrm{Si}$ [30]. The reflectance of SiNWs sample decreases compared to the planar Si substrate and remained less than $20 \%$ compared to planar Si wafer (38\%) in the range of $300-1000 \mathrm{~nm}$. This is attributed to the subwavelength light trapping and the light scattering interactions among the densely packed SiNWs [11, 31, 32]. After PEDOT:PSS coating, the reflectance of both planar Si and SiNWs samples decreases compared to the uncoated samples. In this case, the PEDOT:PSS could be acting as an antireflective coating to reduce the reflectance of $\mathrm{Si}$ layer as mentioned in previous reports $[33,34]$. After $\mathrm{Gr}$ is added, the reflectance of all samples is reduced about $3-5 \%$ compared to the samples coated PEDOT:PSS without Gr. The results demonstrated 


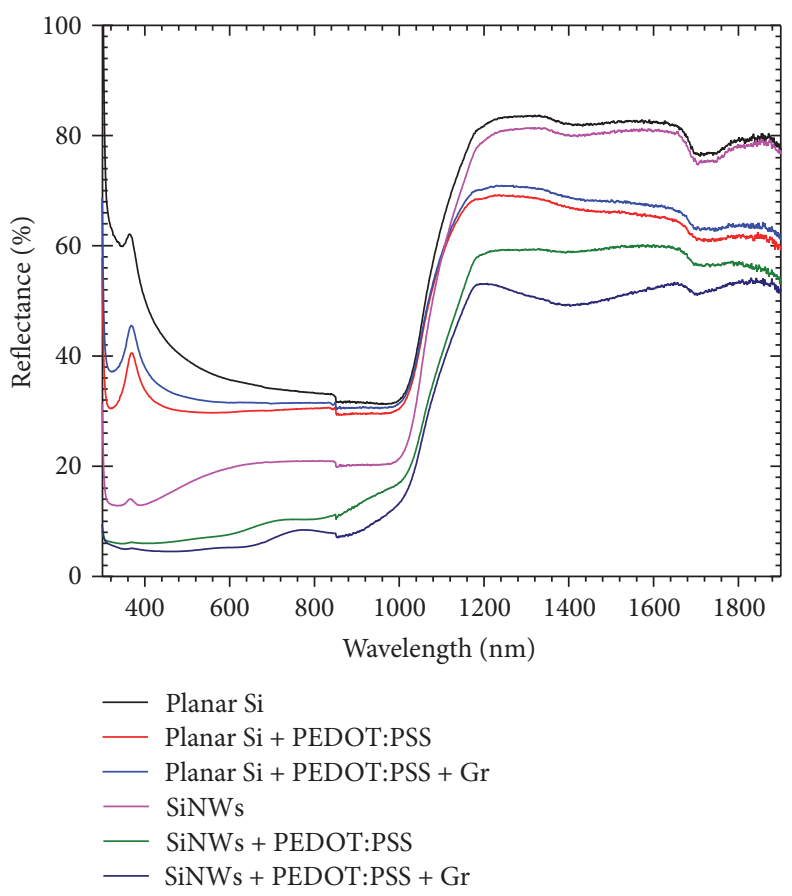

Figure 5: Reflectance spectra of a planar Si wafer, planar Si coated PEDOT:PSS, planar Si coated PEDOT:PSS/Gr, SiNWs, SiNWs coated PEDOT:PSS, and SiNWs coated PEDOT:PSS/Gr.

that the presence of Gr in PEDOT:PSS could help to reduce the reflectance and improve the light trapping effect in solar cell structure by acting as an antireflective material.

The $J-V$ characteristics of the hybrid solar cells were performed under illumination of air mass (AM) 1.5 G. The solar cell parameters such as $V_{\mathrm{oc}}, J_{\mathrm{sc}}, R_{s}, \mathrm{FF}$, and $\eta$ are summarized in Table 1. Figure 6 shows the current-voltage characteristics and solar cell parameters normalized with respect to a cell P0 of hybrid solar planar based cells and SiNWs. The cell P0 showed $\eta$ of $3.69 \%$ with $J_{\mathrm{sc}}$ of $17.34 \mathrm{~mA} \cdot \mathrm{cm}^{-2}, V_{\text {oc }}$ of $0.40 \mathrm{~V}$, and FF of 52\%. By adding Gr to PEDOT:PSS, $\eta$ and $J_{\text {sc }}$ increased, respectively, to $4.36 \%$ and $18.48 \mathrm{~mA} \cdot \mathrm{cm}^{-2}$ for cell P1. FF also increased from 52\% (P0) to 58\% (P1). The same trend was also observed with SiNWs based cells, and $\eta$ increased from $5.32 \%$ (W0) to $6.43 \%$ (W1). Besides, $R_{s}$ of cells containing $\mathrm{Gr}$ is always lower than those of cells without any Gr. $R_{s}$ decreases from $8.03(\mathrm{P} 0)$ to $4.21 \Omega \cdot \mathrm{cm}^{-2}$ (P1) for planar cells and 6.58 (W0) to $3.12 \Omega \cdot \mathrm{cm}^{-2}$ (W1) for SiNWs based cells. Also, it is noted that $\eta$ of the SiNW based cells is always higher than that of planar cells. For example, the cell W1 with $\eta$ of $6.34 \%$ is nearly 1.5 times higher than that of cell P1 (4.36\%). This is attributed to the low reflectance, the good carrier collection at the electrodes, and the effective carrier transportation in the nanowires [32]. The reduction of the reflectance by both the surface morphology and the Gr addition discussed in above section is a good issue that contributed to the increase of the PCE of solar cell $[34,35]$. The interaction between the Gr and PEDOT:PSS can provide additional charge transport pathways in hole transport layer and suppress the electron recombination at the junction interface [34]. In other words, the Gr-PEDOT:PSS interaction will lead to improving the carrier collection efficiency of the PEDOT:PSS hole transporting layer [21, 34].

$J-V$ characteristics of the hybrid solar cells based on SiNWs with Gr dispersed in different media including DI water, EG, and IPA were plotted in Figure 1 and presented in Table 1. We can see that the cell containing Gr dispersed in EG reached to the highest PCE of $7.33 \%$ with $J_{\mathrm{sc}}$ of $22.42 \mathrm{~mA} \cdot \mathrm{cm}^{-2}, V_{\mathrm{oc}}$ of $0.46 \mathrm{~V}$, and $\mathrm{FF}$ of $70 \%$. The PCE enhancement is attributed to the increase in the electrical conductivity, the crystallinity, and the ordering of the PEDOT nanocrystals. The increase in the electrical conductivity of PEDOT:PSS by adding Gr and EG was confirmed by the most reduction of the leakage current density in comparison with others, as shown in Figure 6(b). The effect of EG on the structure and conductivity of PEDOT:PSS has been presented and discussed in several reports [35-40]. Takano et al. reported that, by adding EG in the PEDOT:PSS solution, the electrical conductivity is improved by a factor of 2 orders of magnitude with the growing nanocrystal [36]. Similarly, Wei et al. also confirmed that the enhancement of the electric conductivity of PEDOT:PSS by adding EG resulted from the crystallinity of PEDOT and the ordering of the PEDOT nanocrystals [37]. Besides, because of its higher viscosity compared to DI water and IPA, EG enables keeping the uniform dispersion state of Gr for a longer time and thus avoided the formation of $\mathrm{Gr}$ clusters in the solution. Therefore, we can conclude that EG is the best media for Gr dispersion to obtain the best PCE of SiNW/PEDOT:PSS hybrid solar cell containing functionalized Gr. 


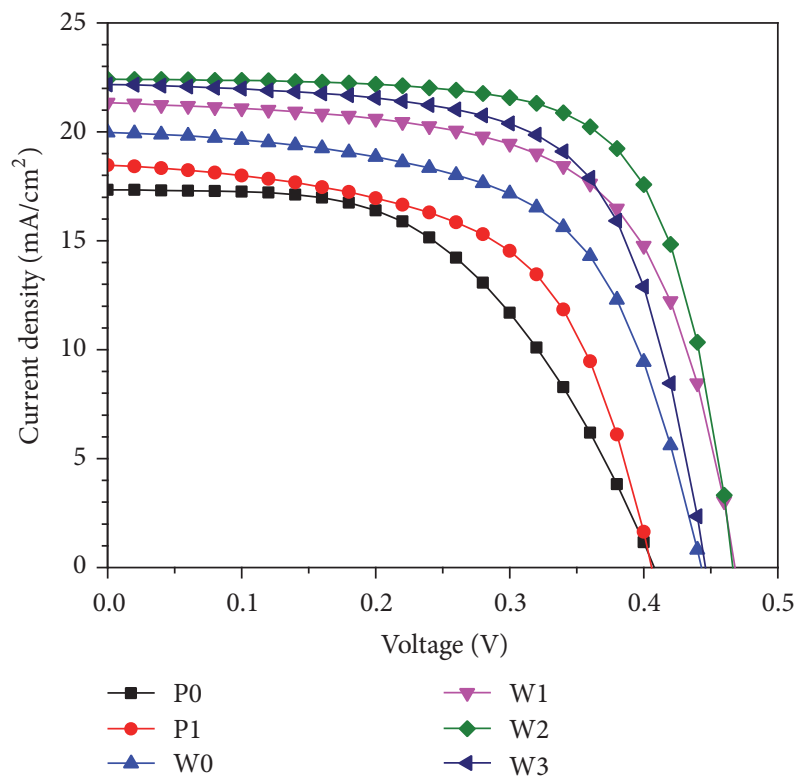

(a)

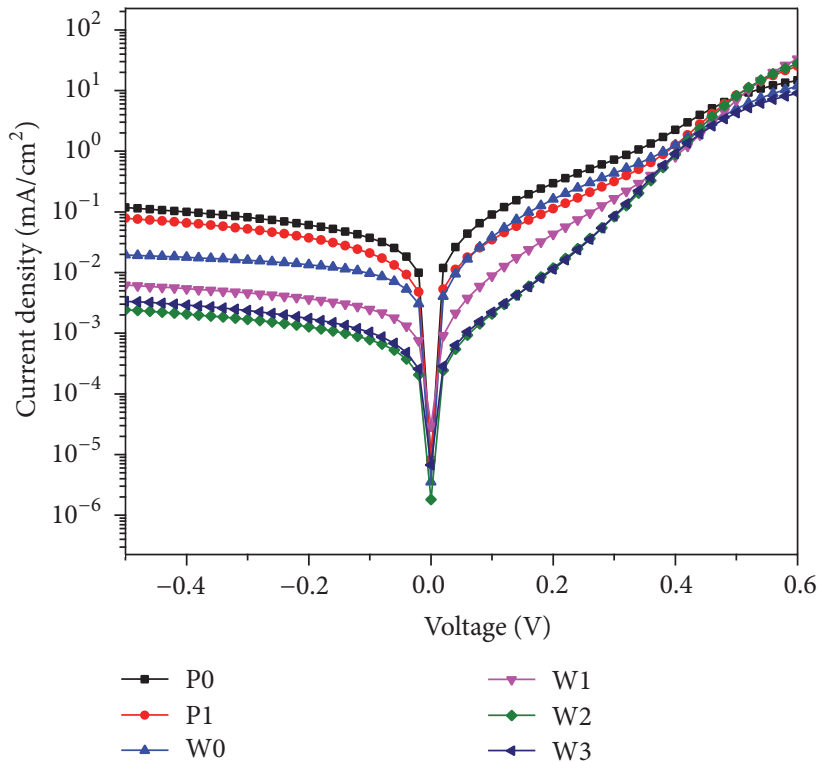

(b)

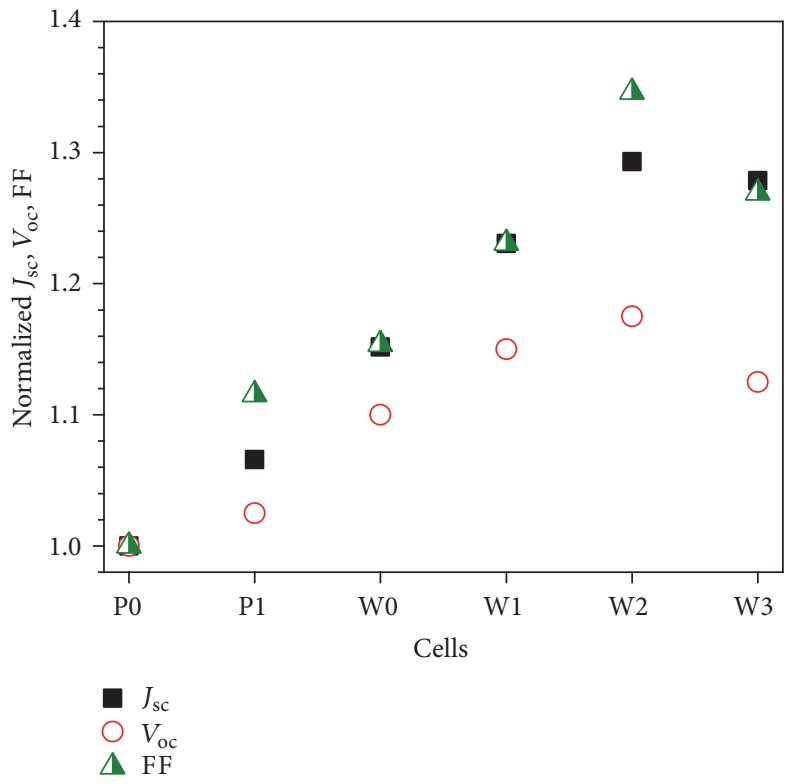

(c)

Figure 6: $J$ - $V$ characteristic (a) under $100 \mathrm{~mW} / \mathrm{cm}^{2}$ illumination with an AM $1.5 \mathrm{G}$ solar simulator and (b) in dark and (c) solar cell parameters normalized with respect to a cell P0 of hybrid solar planar based cells and SiNWs.

\section{Conclusion}

We investigated the results on the effect of surface morphology and dispersion media on the properties of PEDOT: $\mathrm{PSS} / \mathrm{n}$-Si hybrid solar cell containing functionalized Gr. The hybrid solar cells based on SiNWs showed higher PCE compared to the planar based cells. The PCE of hybrid solar cells had improved by adding Gr into PEDOT:PSS solution. Different solvents including DI water, EG, and IPA were used as media for $\mathrm{Gr}$ dispersion. The best performance was obtained with the cell containing Gr dispersed in EG with a measured PCE of $7.33 \%$, nearly $13 \%$, and $16 \%$ enhancement in comparison with the cells using Gr dispersed in IPA and DI water, respectively. As a result, EG is the best dispersion media to obtain the best PCE of PEDOT:PSS/n-Si hybrid solar cell containing functionalized $\mathrm{Gr}$.

\section{Conflicts of Interest}

The authors declare no conflicts of interest regarding this publication. 


\section{Acknowledgments}

This work was mainly supported by the Key Laboratory for Electronic Materials and Devices, Institute of Materials Science, under Project CSTĐ 02.17, and supported by Project VAST.CTVL05/17-18.

\section{References}

[1] R. Yu, Q. Lin, S. F. Leung, and Z. Fan, "Nanomaterials and nanostructures for efficient light absorption and photovoltaics," Nano Energy, vol. 1, no. 1, pp. 57-72, 2012.

[2] Q. Zhang and G. Cao, "Nanostructured photoelectrodes for dye-sensitized solar cells," Nano Today, vol. 6, no. 1, pp. 91-109, 2011.

[3] T. D. Lee and A. U. Ebong, "A review of thin film solar cell technologies and challenges," Renewable \& Sustainable Energy Reviews, vol. 70, pp. 1286-1297, 2017.

[4] P. Yadav, K. Pandey, V. Bhatt, M. Kumar, and J. Kim, "Critical aspects of impedance spectroscopy in silicon solar cell characterization: A review," Renewable \& Sustainable Energy Reviews, vol. 76, pp. 1562-1578, 2017.

[5] O. K. Echendu, K. B. Okeoma, C. I. Oriaku, and I. M. Dharmadasa, "Electrochemical deposition of CdTe semiconductor thin films for solar cell application using two-electrode and three-electrode configurations: A comparative study," Advances in Materials Science and Engineering, vol. 2016, Article ID 3581725, 2016.

[6] P. Yu, J. Wu, S. Liu, J. Xiong, C. Jagadish, and Z. M. Wang, "Design and fabrication of silicon nanowires towards efficient solar cells," Nano Today, vol. 11, no. 6, pp. 704-737, 2016.

[7] T. Song, S.-T. Lee, and B. Sun, "Silicon nanowires for photovoltaic applications: The progress and challenge," Nano Energy, vol. 1, no. 5, pp. 654-673, 2012.

[8] B. Tian, X. Zheng, T. J. Kempa et al., "Coaxial silicon nanowires as solar cells and nanoelectronic power sources," Nature, vol. 449, no. 7164, pp. 885-889, 2007.

[9] G. Yuan, K. Aruda, S. Zhou, A. Levine, J. Xie, and D. Wang, "Understanding the origin of the low performance of chemically grown silicon nanowires for solar energy conversion," Angewandte Chemie International Edition, vol. 50, no. 10, pp. 2334-2338, 2011.

[10] W.-R. Wei, M.-L. Tsai, S.-T. Ho et al., "Above-11\%-efficiency organic-inorganic hybrid solar cells with omnidirectional harvesting characteristics by employing hierarchical photontrapping structures," Nano Letters, vol. 13, no. 8, pp. 3658-3663, 2013.

[11] K. Sato, M. Dutta, and N. Fukata, "Inorganic/organic hybrid solar cells: Optimal carrier transport in vertically aligned silicon nanowire arrays," Nanoscale, vol. 6, no. 11, pp. 6092-6101, 2014.

[12] G. Peng, X. Xu, and G. Xu, "Hybrid organic-inorganic perovskites open a new era for low-cost, high efficiency solar cells," Journal of Nanomaterials, vol. 2015, Article ID 241853, 10 pages, 2015.

[13] X. Yu, X. Shen, X. Mu et al., "High efficiency organic/siliconnanowire hybrid solar cells: significance of strong inversion layer," Scientific Reports, vol. 5, Article ID 17371, 2015.

[14] V. Sivakov, G. Andrä, A. Gawlik et al., "Silicon nanowire-based solar cells on glass: synthesis, optical properties, and cell parameters," Nano Letters, vol. 9, no. 4, pp. 1549-1554, 2009.
[15] M. Wright and A. Uddin, "Organic-inorganic hybrid solar cells: a comparative review," Solar Energy Materials \& Solar Cells, vol. 107, pp. 87-111, 2012.

[16] R. Liu, "Hybrid organic/inorganic nanocomposites for photovoltaic cells," Materials, vol. 7, no. 4, pp. 2747-2771, 2014.

[17] M. R. Alejandro, J. L. N. Edgar, S. Wole, M. V. Yunny, and V. Bertrand, "A review on the efficiency of graphene-based BHJ organic solar cells," Journal of Nanomaterials, vol. 2015, Article ID 406597, 15 pages, 2015.

[18] F. C. Krebs, T. D. Nielsen, J. Fyenbo, M. Wadstrom, and M. S. Pedersen, "Manufacture, integration and demonstration of a lamp for the "Lighting Africa" initiative," Energy and Environmental Science, vol. 3, pp. 512-525, 2010.

[19] Y. Zhou, C. Fuentes-Hernandez, J. Shim et al., "A universal method to produce low-work function electrodes for organic electronics," Science, vol. 336, no. 6079, pp. 327-332, 2012.

[20] K. Uma, T. Subramani, H.-J. Syu, T.-C. Lin, and C.-F. Lin, "Fabrication of silicon nanowire/poly(3,4-ethylenedioxythiophene):poly(styrenesulfonate)-graphene oxide hybrid solar cells," Journal of Applied Physics, vol. 117, no. 10, Article ID 105102, 2015.

[21] T. Song, S.-T. Lee, and B. Sun, "Prospects and challenges of organic/group IV nanomaterial solar cells," Journal of Materials Chemistry, vol. 22, no. 10, pp. 4216-4232, 2012.

[22] J. S. Kim, S. Wood, S. Shoaee et al., "Morphology-performance relationships in polymer/fullerene blends probed by complementary characterisation techniques - Effects of nanowire formation and subsequent thermal annealing," Journal of Materials Chemistry C, vol. 3, no. 35, pp. 9224-9232, 2015.

[23] Z. Yin, J. Zhu, Q. He et al., "Graphene-Based materials for solar cell applications," Advanced Energy Materials, vol. 4, no. 1, Article ID 1300574, 2014.

[24] D. Van Thanh, L.-J. Li, C.-W. Chu, P.-J. Yen, and K.-H. Wei, "Plasma-assisted electrochemical exfoliation of graphite for rapid production of graphene sheets," RSC Advances, vol. 4, no. 14, pp. 6946-6949, 2014.

[25] V. T. Pham, M. Dutta, H. T. Bui, and N. Fukata, "Effect of nanowire length on the performance of silicon nanowires based solar cell," Advances in Natural Sciences: Nanoscience and Nanotechnology, vol. 5, no. 4, Article ID 045014, 2014.

[26] P. Van Trinh, N. N. Anh, B. H. Thang et al., "Enhanced thermal conductivity of nanofluid-based ethylene glycol containing $\mathrm{Cu}$ nanoparticles decorated on a Gr-MWCNT hybrid material," RSC Advances, vol. 7, no. 1, pp. 318-326, 2017.

[27] T. Lindfors, Z. A. Boeva, and R.-M. Latonen, "Electrochemical synthesis of poly(3,4-ethylenedioxythiophene) in aqueous dispersion of high porosity reduced graphene oxide," RSC Advances, vol. 4, no. 48, pp. 25279-25286, 2014.

[28] J. Ouyang, Q. Xu, C.-W. Chu, Y. Yang, G. Li, and J. Shinar, "On the mechanism of conductivity enhancement in poly $(3,4$ ethylenedioxythiophene):poly(styrene sulfonate) film through solvent treatment," Polymer Journal, vol. 45, no. 25, pp. 84438450, 2004.

[29] P. G. Raj, V. S. Rani, A. Kanwat, and J. Jang, "Enhanced organic photovoltaic properties via structural modifications in PEDOT:PSS due to graphene oxide doping," Materials Research Bulletin, vol. 74, pp. 346-352, 2016.

[30] T. Yoshida, M. Sakai, and T. Tanabe, "In-situ optical reflection measurement of a $\mathrm{Si}(100)$ surface under hydrogen ion irradiation," Materials Transactions, vol. 45, no. 7, pp. 2018-2022, 2004. 
[31] M. Dutta and N. Fukata, "Effect of shell growth and doping conditions of core-shell homojunction si nanowire solar cells," Journal of Nanoscience and Nanotechnology, vol. 15, no. 6, pp. 4339-4346, 2015.

[32] M. Dutta, L. Thirugnanam, P. V. Trinh, and N. Fukata, "High efficiency hybrid solar cells using nanocrystalline si quantum dots and si nanowires," ACS Nano, vol. 9, no. 7, pp. 6891-6899, 2015.

[33] Q. Liu, R. Ishikawa, S. Funada, T. Ohki, K. Ueno, and H. Shirai, "Highly efficient solution-processed poly(3,4-ethylenedioxythiophene):poly(styrenesulfonate)/crystalline-silicon heterojunction solar cells with improved light-induced stability," Advanced Energy Materials, vol. 5, no. 17, Article ID 1500744, 2015.

[34] X. Jiang, Z. Wang, W. Han et al., "High performance siliconorganic hybrid solar cells via improving conductivity of PEDOT:PSS with reduced graphene oxide," Applied Surface Science, vol. 407, pp. 398-404, 2017.

[35] J. P. Thomas and K. T. Leung, "Mixed co-solvent engineering of PEDOT:PSS to enhance its conductivity and hybrid solar cell properties," Journal of Materials Chemistry A, vol. 4, no. 44, pp. 17537-17542, 2016.

[36] T. Takano, H. Masunaga, A. Fujiwara, H. Okuzaki, and T. Sasaki, "PEDOT nanocrystal in highly conductive PEDOT:PSS polymer films," Macromolecules, vol. 45, no. 9, pp. 3859-3865, 2012.

[37] Q. Wei, M. Mukaida, Y. Naitoh, and T. Ishida, "Morphological change and mobility enhancement in PEDOT:PSS by adding co-solvents," Advanced Materials, vol. 25, no. 20, pp. 2831-2836, 2013.

[38] Y.-J. Lin, W.-S. Ni, and J.-Y. Lee, "Erratum: Effect of incorporation of ethylene glycol into PEDOT:PSS on electron phonon coupling and conductivity," Journal of Applied Physics, vol. 117, no. 21, Article ID 219901, 2015.

[39] H. Okuzaki, Y. Harashina, and H. Yan, "Highly conductive PEDOT/PSS microfibers fabricated by wet-spinning and diptreatment in ethylene glycol," European Polymer Journal, vol. 45, no. 1, pp. 256-261, 2009.

[40] T. Etampawala, M. Tehrani, A. Nematollahi, L. He, and M. Dadmun, "The impact of solvent doping on the morphology and performance of spray-coated PEDOT:dPSS: A USANS and SANS study," Organic Electronics, vol. 51, pp. 86-93, 2017. 

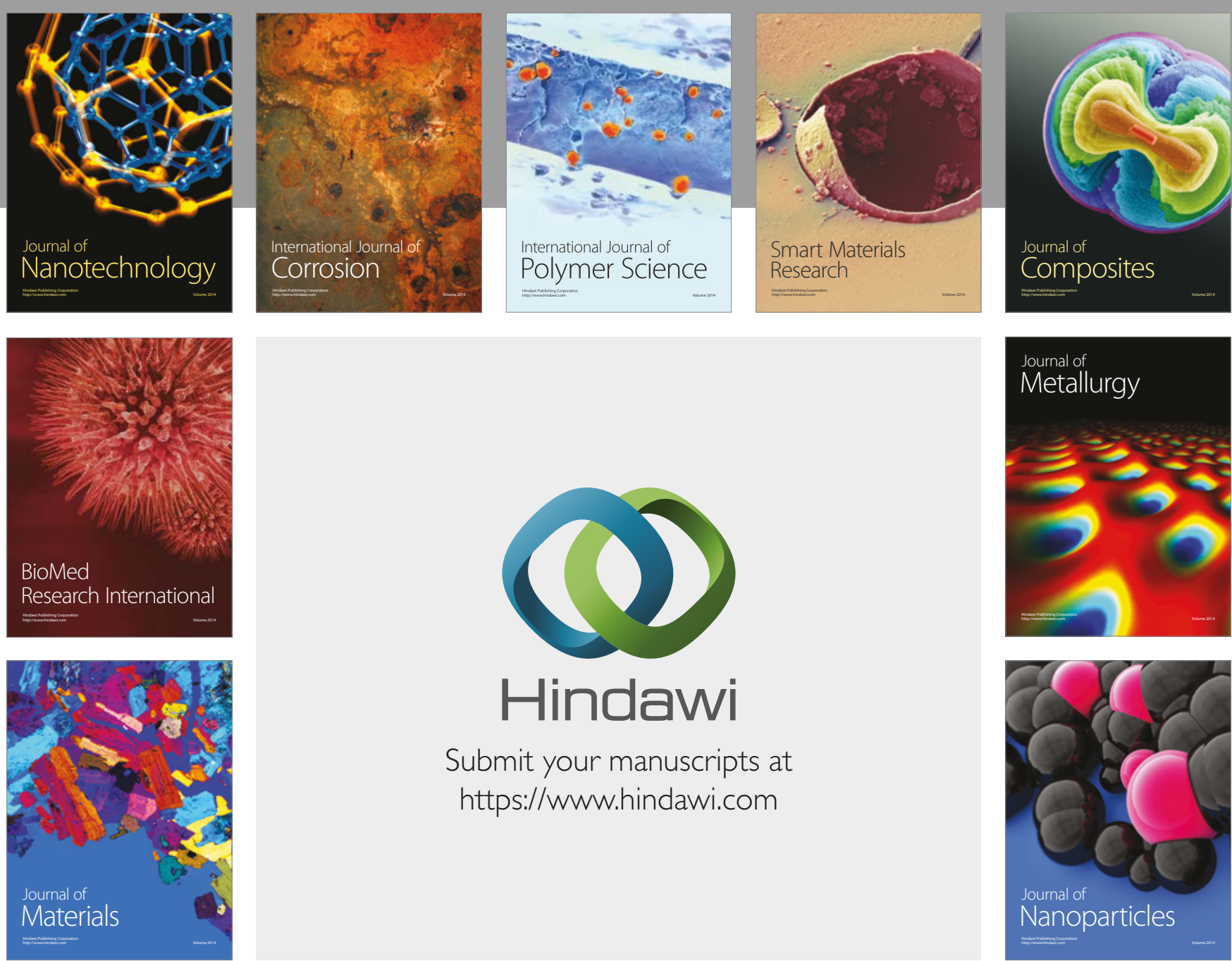

\section{Hindawi}

Submit your manuscripts at

https://www.hindawi.com
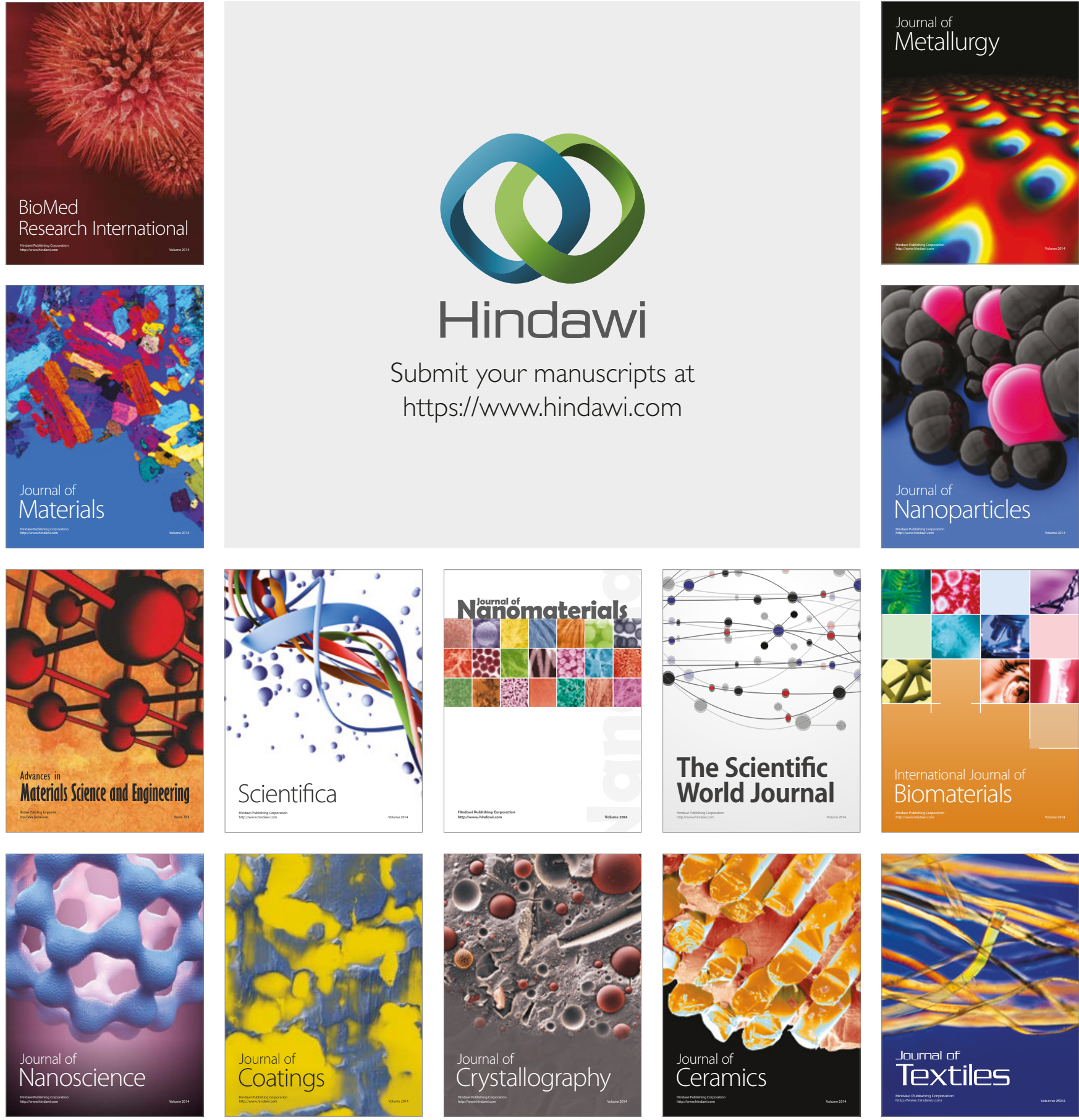

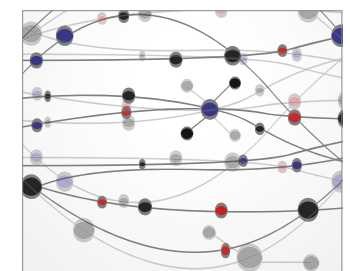

The Scientific World Journal
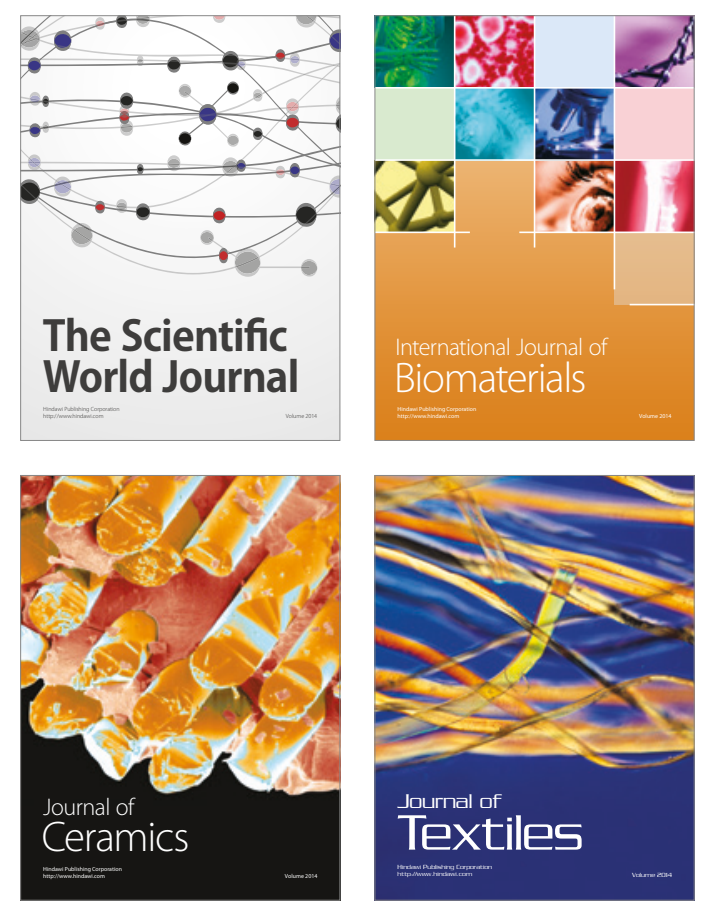